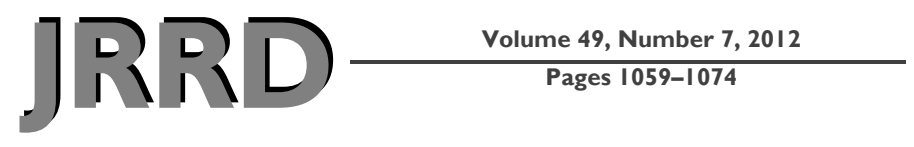

\title{
Implications of blast exposure for central auditory function: A review
}

\author{
Frederick J. Gallun, PhD; ${ }^{1-2 *}$ M. Samantha Lewis, PhD; ${ }^{1-2}$ Robert L. Folmer, PhD; ${ }^{1-2}$ Anna C. Diedesch, \\ AuD; ${ }^{1}$ Lina R. Kubli, MS; ${ }^{3}$ Daniel J. McDermott, MS; ${ }^{1}$ Therese C. Walden, AuD; ${ }^{3}$ Stephen A. Fausti, PhD; ${ }^{1-2}$ \\ Henry L. Lew, MD, PhD; ${ }^{4}$ Marjorie R. Leek, PhD $^{1-2}$ \\ ${ }^{1}$ Department of Veterans Affairs (VA) Rehabilitation Research and Development National Center for Rehabilitative \\ Auditory Research (NCRAR), Portland VA Medical Center, Portland, OR; ${ }^{2}$ Oregon Health \& Science University, Port- \\ land, OR; ${ }^{3}$ Audiology and Speech Center, Walter Reed National Military Medical Center (WRNMMC), Bethesda, MD; \\ ${ }^{4}$ Defense and Veterans Brain Injury Center (DVBIC), Richmond, VA
}

\begin{abstract}
Auditory system functions, from peripheral sensitivity to central processing capacities, are all at risk from a blast event. Accurate encoding of auditory patterns in time, frequency, and space are required for a clear understanding of speech and accurate localization of sound sources in environments with background noise, multiple sound sources, and/or reverberation. Further work is needed to refine the battery of clinical tests sensitive to the sorts of central auditory dysfunction observed in individuals with blast exposure. Treatment options include low-gain hearing aids, remote-microphone technology, and auditory-training regimens, but clinical evidence does not yet exist for recommending one or more of these options. As this population ages, the natural aging process and other potential brain injuries (such as stroke and blunt trauma) may combine with blast-related brain changes to produce a population for which the current clinical diagnostic and treatment tools may prove inadequate. It is important to maintain an updated understanding of the scope of the issues present in this population and to continue to identify those solutions that can provide measurable improvements in the lives of Veterans who have been exposed to high-intensity blasts during the course of their military service.
\end{abstract}

Key words: auditory dysfunction, auditory processing disorder, blast, central auditory dysfunction, central auditory processing, central auditory system, hearing loss, rehabilitation, traumatic brain injury, veteran.

\section{INTRODUCTION}

When auditory dysfunction is considered in relation to blast exposure, the most immediate concern is peripheral damage. While peripheral auditory dysfunction is commonly associated with traumatic injury due to blast exposure [1-8], there also is an increasing awareness of the vulnerability of the central auditory nervous system (CANS) to blast-induced injury [9-11]. Much of the interest in central dysfunction and traumatic brain injury (TBI) has focused on damage to executive functions such as memory and attention, but recent modeling [12], animal

\footnotetext{
Abbreviations: $\mathrm{AF}=$ arcuate fasciculus, CANS $=$ central auditory nervous system, CAPD = central auditory processing disorder, DTI = diffusion tensor imaging, fMRI = functional magnetic resonance imaging, OIF/OEF/OND = Operation Iraqi Freedom/Operation Enduring Freedom/Operation New Dawn, PTSD = posttraumatic stress disorder, RR\&D = Rehabilitation Research and Development, STRF = spectrotemporal receptive field, TBI = traumatic brain injury, VA = Department of Veterans Affairs.

*Address all correspondence to Frederick J. Gallun, PhD; VA RR\&D National Center for Rehabilitative Auditory Research, 3710 SW U.S. Veterans Hospital Rd, Portland, OR 97239; 503-220-8262, ext 57472; fax: 503-721-1402. Email: Frederick.Gallun@va.gov http://dx.doi.org/10.1682/JRRD.2010.09.0166
} 
studies [13], reviews of blast injuries [1], and human imaging studies [14] have converged to demonstrate the high likelihood that blast exposure will result in injury that could have substantial impacts on the central auditory system as well. Among the potential effects of blast exposure on the brain, contusions, blood vessel injury, and/or axonal injury are insults that can result in focal lesions and/or diffuse injury to the neuronal cell bodies and axons of one or more of the main brain regions involved in auditory processing. Given the widely distributed and reciprocally connected organization of the CANS and the potential for broad patterns of damage on the cellular level in addition to well-defined lesions to particular brain areas, it is difficult to make simple predictions about what the implications of blast exposure will be for auditory processing. While increasing attention is being given to the interconnected nature of the systems that may be damaged, it is important not to overlook the complexity of the anatomical and physiological organization of the central auditory system itself.

One particularly difficult issue for identifying the relationships between sites of injury and functional impairments is that the functioning of the CANS depends upon the reciprocal flow of excitatory and inhibitory signals in response to changing stimulation and task demands [15-16]. The functional implications of widespread damage to this system are currently unknown, but several potential areas in which deficits might be noticed by the patient would include increased difficulties communicating in complex acoustical environments, errors in the identification and localization of sound sources in the environment, and decreased sensitivity to musical patterns, which could result in a reduced appreciation of music. It is easy to imagine that both the clinician and the patient could be confused and dismayed at the apparently abstract and unconnected nature of the symptoms observed. Diagnosis and treatment of such a constellation of symptoms has the potential to pose novel problems that can only be adequately addressed by referring to a model of the CANS that is currently far from complete at either the neural or the functional level. It is also the case that central auditory system functions overlap with and depend upon executive functions, working memory, and visual function. In addition, normal performance on tests often depends upon normal attentional and emotional function. Consequently, an interdisciplinary team that includes experts familiar with the many areas of potential dysfunction will be necessary to accurately evaluate and treat any individual patient [7]. It is helpful to be aware that, despite the many overlaps in function, there are still a number of organizing principles that can be used to distinguish auditory function from the other systems that may also be affected by blast exposure and TBI. Knowledge of the distinct areas of function related to the central auditory system can thus be used to guide clinical evaluation, rehabilitation, and future research.

\section{METHODS}

This review was conducted by consulting the literature on blast exposure in the context of the functions of the central auditory system. These results were then compared with the data on central auditory deficits associated with blast exposure. Finally, implications for rehabilitation were considered. Given the paucity of data available in each of these areas, the main goal of this review is to indicate the areas in which further research is needed and to articulate specific hypotheses that are consistent with the data and patient complaints that are available.

\section{RESULTS}

\section{Central Auditory Nervous System Sites Potentially Damaged by Blast Exposure}

The passage of a high-intensity blast wave through the brain generates differential pressure gradients [1213], resulting in what is known as primary blast injury. In addition, the motion of the human body and the impacts of other objects on the body, known as secondary and tertiary blast injury, can result in the skull impacting the brain [14]. Subjecting the brain to pressure gradients through primary injury and other mechanical forces through secondary and tertiary injury can result in the stretching or shearing of neural projections in the auditory pathways [17] as well as contusions to the surface of the brain, injury to blood vessels, and inflammatory changes in response to tissue injury [18]. In addition to the possibility of damaging the integrity of nuclei at the level of the brainstem, thalamus, and cortex, there also may be a loss of synaptic structures and neural connections throughout the central auditory system, including the corpus callosum, all of which could result in distorted or missing information at the level of the cortex [19-20]. While the majority of this review focuses on the potential 
effects of primary blast injury, it is important to note that little or no data exist that can be used to distinguish among the various mechanisms at a functional level. This is an essential gap in our knowledge of the relationship between blast exposure and central auditory processing, and one that is essential to fill in order to provide improved recommendations for the triage and treatment of blast exposure.

As shown schematically in the Figure, the ascending central auditory pathways begin with the termination of the auditory nerve at the cochlear nucleus and extend through the brainstem, thalamus, and corpus callosum before terminating in the primary auditory cortex, located in the superior temporal gyrus. The majority of the ascending projections from each auditory nerve cross the brainstem at the pons to innervate the contralateral midbrain at the level of the inferior colliculus, from which projections extend to the medial geniculate nucleus of the thalamus and eventually reach the temporal cortex on the opposite side of the brain from the cochlea, providing the initial sensory encoding [21]. Consequently, the primary auditory cortex on each side of the brain is sensitive to stimulation through either ear but is more strongly driven by contralateral stimulation.

While the precise organization of the human auditory cortex is not well understood and currently under intense study, the primary auditory cortex in mammals has been found to be surrounded by as many as 11 distinct regions, each devoted to processing a particular functional dimension of auditory information [22-23]. Petkov et al. discovered distinct regions of temporal cortex in the brains of Macaque monkeys sensitive to vocalizations and musical instruments [23]. Similarly, Leaver and Rauschecker demonstrated that regions of the human auditory cortex are selective for human speech and musical instrument sounds, suggesting that the other patterns of sensitivity revealed in primate brains may exist in the human auditory cortex as well [24]. Furthermore, Leaver and

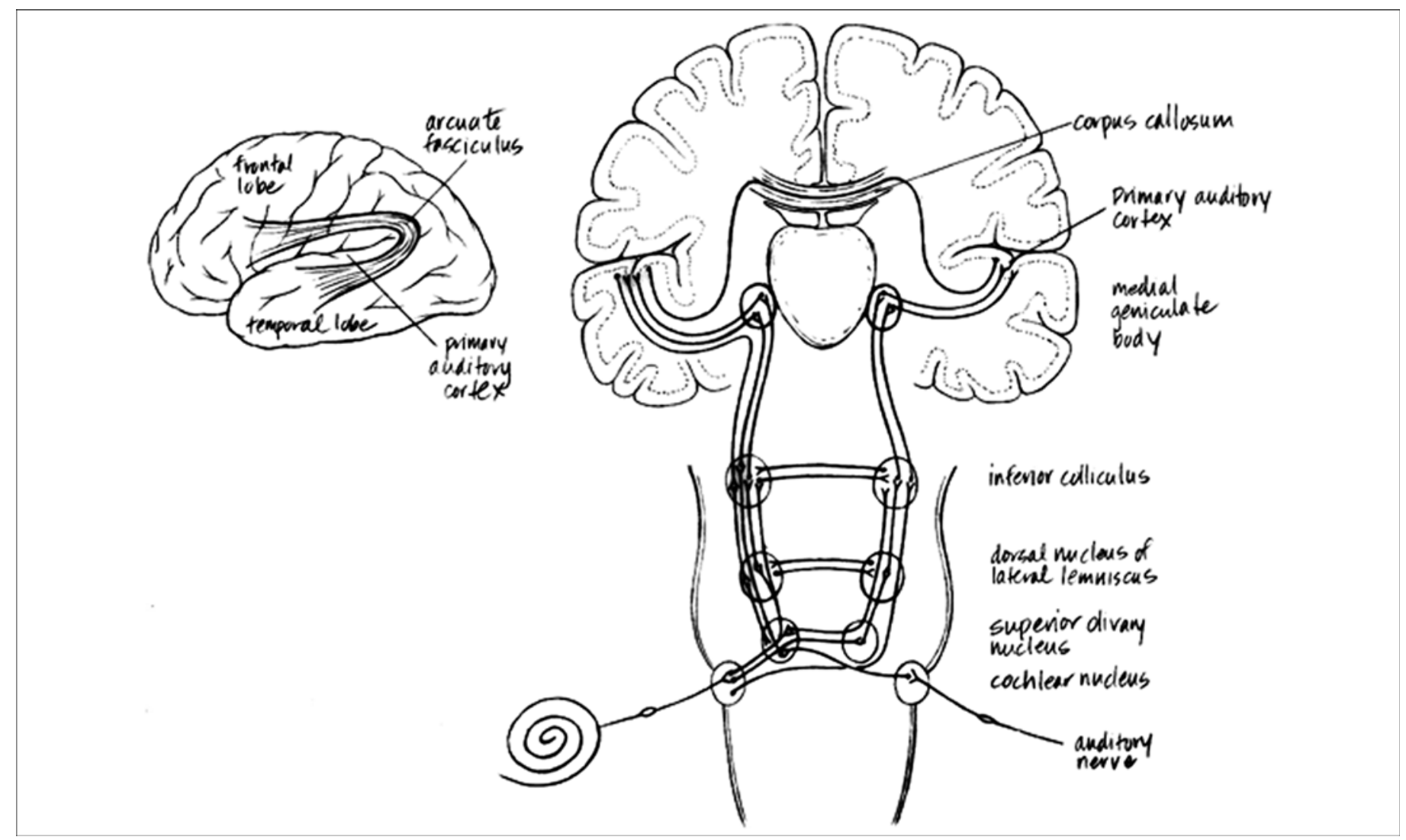

Figure.

Schematic representation of organization of central auditory system [15,21-29]. 
Rauschecker also demonstrated that the temporal cortex contains a hierarchy of processing in which areas closer to the primary auditory cortex are involved in encoding specific acoustical features and regions further away from the primary auditory cortex are more involved in the categorical processing of auditory objects independent of spectral or temporal acoustical signatures [24]. These data are consistent with an organization of auditory cortex in which "auditory objects," such as representations of voices, musical instruments, or other environmental sound sources, are represented in specific cortical regions on the basis of coordinated input from neural populations earlier in the pathway that encode individual auditory features [25]. As Winer and Lee point out, however, it is important to keep in mind the role of descending inhibitory connections as well [15]. These modulatory influences are likely to be essential for allowing the listener to flexibly reorganize the sensitivity of auditory cortical regions in response to changing task and stimulus parameters [16]. In addition to those purely auditory regions found in the temporal lobe, auditory processing and/or modulation and transfer of auditory information occurs in a number of regions in the frontal and parietal cortical areas, as well as the corpus callosum, which connects the two hemispheres. It is now wellestablished that there are cortical and subcortical structures throughout the brain that are intimately involved in the processing of auditory information, particularly in terms of the neural networks supporting the comprehension of speech [26].

\section{Potential Behavioral Implications of Central Damage}

\section{Sound Source Identification Errors}

Spectrotemporal pattern distortions. Current functional models of the primary auditory cortex $[25,27]$ suggest that the information extracted from the acoustic signal by the brainstem and thalamic processing stages is represented at the cortical level as clusters of spectral and harmonic patterns across a range of time scales, often referred to as spectrotemporal receptive fields (STRFs). It has been suggested that the shapes of these STRFs are adaptively updated on an ongoing basis as a function of the salient spectral and temporal properties of behaviorally relevant acoustic stimulation $[16,28]$. Long-lasting changes in STRF shape (over the course of hours) suggest that this plasticity may contribute to the basic operations of long-term sensory memory. Functional neuroimaging reveals changes in the patterns of neu- ral activity at the level of the auditory cortex before and after participants learned novel speech tasks (reviewed by Zatorre [29]). Such changes are consistent with a model of auditory processing in which the basic sensitivity of auditory cortical systems is reorganized based on the behavioral relevance of acoustical stimuli. If this basic model is correct, then distortions or missing information caused by poor signal integrity at the level of the brainstem and/or thalamus would result in erroneous mismatches between the stored representations of patterns related to particular sound sources and the incoming stimulation. This would reduce the ability of listeners to identify phonemic information and to rapidly identify alerting sounds in the environment such as fire alarms, train crossing signals, or car horns.

It is possible that identification of spectrotemporal patterns would occur successfully in situations in which the signals presented were of long duration and the background noise was low but that errors would begin to occur as soon as the stream of information was presented at a more rapid rate or interfering sounds were present. Distortions at the level of the STRF would be problematic when stimuli were presented rapidly, since one of the basic dimensions of the STRF is changes in intensity over time. If the input to the neural structures responsible for the STRF was reduced in its temporal precision because of variability in axonal transmission times, it would be quite likely that rapid modulations of sounds would become undetectable on the basis of the STRF.

Other difficulties patients with central auditory damage might experience involve the identification of competing speech stimuli presented simultaneously. Such difficulties would be predicted based on the hypothesis that when two similar inputs activate similar STRFs, there is more interference than if the interference takes the form of random noise with little spectrotemporal structure. This would imply greater interference for competing speech or rapidly changing environmental noises, such as clanking dishes and silverware, than for traffic noise or running water, for example. While there is substantial evidence for this sort of "informational masking" in listeners with intact auditory systems [30], there have never been systematic investigations of the extent to which susceptibility to informational masking is increased by injury to the central auditory system. Based on the STRF model of auditory perception and associated distortions, however, it seems quite likely that informational-masking paradigms may be particularly good candidates for tests that are sensitive to central auditory dysfunction. 
Sensory memory encoding and retrieval. Human auditory memory has not been studied in sufficient detail by neuroscientists to allow definitive hypotheses to be generated, but the work that does exist (reviewed by Demany and Semal [31]) points directly to the idea that many fundamental recognition abilities rely upon comparisons of neural representations generated, encoded, and then retrieved by the central auditory system. Consistent with this idea, work on the measurement and modeling of STRF shapes [27-28], showing the rapid plasticity of these representations, may be the basis for sensory memory encoding and retrieval in the central auditory system. The learning studies reviewed by Zatorre are also consistent with the idea that auditory cortex reorganization occurs when new auditory stimuli are committed to memory [29]. Such a suggestion implies that distortions at the level of spectrotemporal representations would not only interfere with the recognition of expected patterns but would also reduce the ability of listeners to efficiently adapt to new behaviorally relevant acoustic patterns over longer time scales. An additional hypothesis is that any distortions to the neural codes that form the basis of these comparisons of sensory input are likely to result in a decrease in the resolution and accuracy of patterns encoded after injury relative to those encoded prior to injury. Such a hypothesis suggests that listeners might be more accurate at recognizing spectrotemporal patterns learned before injury than newer ones learned after injury. This could potentially affect the ability to recognize speech patterns of new acquaintances or to learn new auditory tasks, such as those associated with jobrelated functions. At the present time, however, there are no data available for testing these hypotheses.

\section{Pitch and Pitch Sequencing}

Pitch extraction errors. According to most functional models of the central auditory system (e.g., $[27,32])$, one of the most fundamental pieces of information extracted by the auditory system is pitch. This dimension of auditory experience is a function of both the parts of the cochlea that are most strongly stimulated and the temporal rate at which stimulation occurs. Although much argument still exists about the precise mechanisms by which pitch is extracted [33-34], it is clear that the information necessary for encoding both the spectral and temporal aspects of pitch exists as early in the processing chain as the auditory nerve, and the representations of information related to pitch extraction are found in substantial portions of the brainstem (reviewed by Joris et al. [35]). The peripheral nature of pitch extraction is consistent with the finding that pitch perception is substantially impaired in listeners with cochlear hearing loss [36-38], whether this is measured using comparisons of the frequencies of pure tones or the perceived pitch strength of more complex stimuli. These effects seem to be due to both the broadening of activity in the cochlea in response to a spectrally restricted input, such as a pure tone, and the introduction of variability in the temporal patterns generated on the auditory nerve in response to a regular input, such as a low-frequency pure tone or a rapidly modulated broadband stimulus.

While it is often the case that blast exposure leads to cochlear damage, it is possible that pitch extraction based on temporal factors could be impaired on the basis of damage to neural tracts, such as the auditory nerve, which first encodes the temporal pattern, or regions of the auditory brainstem, which serve to transform the code from a direct analog representation to a representational or symbolic code based on the rate at which neural impulses occur [35]. Joris et al. suggest that the final transformation from an analog code to a symbolic code may only occur at the inferior colliculus, which is the last processing stage of the brainstem [35]. Consequently, the stretching, shearing, and swelling of neural fibers in the brainstem could be the cause of pitch-extraction errors, even in cases in which only minimal cochlear dysfunction is present. To date, no studies exist that could be used to determine the extent to which pitch and frequency resolution is impaired by blast exposure, but it would be likely that only those subjects with damage to the brainstem would exhibit such difficulties.

Pitch pattern identification reductions. More common in batteries of tests for central auditory processing disorder (CAPD) than tests of pitch- or frequency-difference limens are tests of frequency-pattern identification. While Musiek and Pinheiro showed that brainstem lesions are associated with an increased chance of making errors in a test of frequency-pattern identification (45\% of subjects with brainstem lesions as compared with $12 \%$ of those with cochlear hearing loss but no brainstem or cortical dysfunction) [39], the strongest relationship was found in subjects with cortical lesions, where 89 percent of the patients tested made errors on 25 percent or more of the identification trials. The distributed nature of the information needed to perform this task is indicated by the diversity of cortical lesions exhibited by the patients who performed poorly in Musiek and Pinheiro's 
study [39]. Not only were there patients with temporal lobe lesions in one or both hemispheres, but there were subjects with frontal and/or parietal lobe lesions with damage to the insular cortex. Insular cortex lesions have been shown to result in impaired performance on several different auditory pattern identification tasks [40].

The involvement of multiple cortical areas is consistent with Musiek and Pinheiro's hypothesis that good performance on this task requires not only the effective processing of frequency at the level of the cochlea and the brainstem but also the faithful transmission of this information to the primary auditory cortex for coding as a series of discrete auditory objects with unique frequency content [39]. The task does not end there, however, since the subject must identify the order in which three tones differing in frequency have been presented (i.e., "lowlow-high" or "low-high-low"). As at least one tone of each frequency is presented on each trial, only by correctly identifying the contour of the pattern can correct identification be achieved. Rapid processing, such as that associated with speech, is thought to occur in the left temporal lobe, while slower processing, such as that associated with music, has been suggested to occur in the right temporal lobe (reviewed by Tervaniemi and Hugdahl [41]). This dichotomy suggests that the right hemisphere would perform the sequencing task and the left hemisphere would be involved in the verbal response. Such transfer of information would require intact communication between the hemispheres as well, implicating an important role for the corpus callosum [39].

An additional pathway important for labeling pitch has recently been uncovered in the arcuate fasciculus (AF) [42], which is a fiber tract connecting frontal and temporal areas (Figure). Not only is tone deafness (the inability to label pitches) associated with smaller AF volumes, but 20-minute sessions of transcranial directcurrent stimulation of the area in which the AF is located resulted in diminished accuracy in a pitch-matching task [43]. Accuracy was not affected when the device was used to present a "sham" stimulation (which subjects did not report as distinguishable from the true stimulation) in which the device was applied but the current was reduced 30 seconds after the stimulation started.

The possibility that frequency-pattern identification relies upon such a complex and interconnected network suggests that such pattern identification abilities could be particularly susceptible to injury. On the other hand, the frequencies used in the test are so different from each other $(880 \mathrm{~Hz}$ and $1,122 \mathrm{~Hz}$ ) that even a distorted representation might still be identified accurately, as Musiek and Pinheiro reported for their subjects with hearing impairment [39]. Despite the high probability that such a group would have substantially increased pitch discrimination thresholds [37], only 12 percent of Musiek and Pinheiro's cochlear hearing loss group actually had difficulty identifying the patterns. This distinction between distortions at the level of precise pitch extraction and interference with the encoding and/or identification of broader pitch contours may provide an important way to distinguish cortical damage associated with focal lesions (such as strokes and tumors) from the axonal/cochlear damage that is hypothesized to be associated with exposure to high-intensity blasts.

\section{Difficulties Communicating in Complex Acoustical Environments}

Spatial benefit. The locations of sound sources in space are coded by the auditory system at the level of the brainstem (reviewed by Colburn and Durlach and Stecker and Gallun [44-45]) and then transmitted to the cortex. At the level of the cortex, spatial information can be combined with spectrotemporal information to form representations of auditory objects that are then available to other cortical systems involved in the sorting and selection of behaviorally relevant stimuli $[32,46]$. "Binaural" processing relies heavily upon the comparisons of the precise temporal relationships among neural patterns arriving from the two ears. Comparison of these patterns allows the brainstem nuclei associated with binaural processing to extract the interaural differences in time of arrival of the sounds at the two ears. These interaural differences are then used to associate locations in space with the sources of the sounds that arrive at the two ears. Increasing the variability of the temporal patterns of neural activity at the level of the auditory nerve, cochlear nucleus, or medial trapezoidal body would affect the ability of neural comparison mechanisms to extract this information, which requires discriminations on the time scale of tens of microseconds (millionths of a second). For this reason, sensitivity could be impaired in individuals with blast exposure to the point where binaural timing differences are essentially erased without any substantial resulting change in sensitivity to the presence or general pitch range of a pure tone.

While the ability to identify the location of an object in space is important for maintaining awareness of the 
spatial geometry of the world around us, it is also extremely beneficial in reducing the interference from environmental noise. This is especially true when the interfering stimulation is irrelevant speech. Kidd et al. demonstrated that listeners who are informed where to listen in space perform substantially better on a test of speech intelligibility when there are three possible targets, relative to listeners who are not told in advance where to listen [47]. Using a similar test, Marrone et al. showed that spatially separating a target talker from an interferer by only $15^{\circ}$ could improve speech intelligibility as much as if the talkers were presented from the same loudspeaker with the masker reduced in level by approximately $8 \mathrm{~dB}$ [48]. Further separations (of target and masker) increased the improvement with spatial cues ("spatial release") by another $4 \mathrm{~dB}$. In that experiment, reverberation, which reduces interaural timing information [49], was shown to reduce spatial release by as much as $4 \mathrm{~dB}$. Marrone et al. went on to demonstrate that both age and hearing loss can combine to result in additional reductions in spatial release [50]. The effect was especially clear in the reverberant environment, in which older listeners with hearing loss received only $1.5 \mathrm{~dB}$ of benefit while young listeners with normal hearing received almost $8 \mathrm{~dB}$ of benefit from displacing the interfering talkers by $90^{\circ}$ to the left and to the right of the centrally located target talker.

The extent to which blast exposure affects binaural processing is currently unknown, but it is not difficult to imagine the fragility of a process that relies upon microsecond timing accuracy in the transmission of spikes conducted through several synapses before being compared at the level of the brainstem. Added to the possible disruptions in neural timing due to blast exposure, the demonstrated effects of age and hearing loss on binaural abilities suggest that as the blast-exposed person ages, spatial hearing and spatial benefit in complex situations could be substantially reduced. Such a reduction is likely to result in an increased number of audiological complaints that may be very difficult to diagnose based on pure-tone sensitivity alone.

Spectrotemporal grouping. In addition to spatial cues, listeners are sensitive to a range of spectral and temporal differences between sound sources in the environment. Experiments employing artificial stimuli have been used extensively in pursuit of a deeper understanding of the ways in which the auditory system organizes incoming stimuli into coherent objects (also referred to as sources, streams, groups, or patterns, depending on the context). The phenomenon of "perceptual grouping” was introduced by Gestalt psychologists, such as Köhler, who argued that the nervous system does not process independent local events or stimulations, but groups these local occurrences into a pattern in space and/or time [51]. Furthermore, he argued, the biological response is not to the local occurrences but to the pattern that is formed. The Gestalt grouping principles originally described for visual stimuli have auditory analogs as well, and it has been demonstrated that many of these principles have been exploited in both classical and traditional folk music traditions for hundreds of years [52-53]. The evidence for and utility of spectrotemporal and spatial pattern recognition by human [54] and machine [55] observers makes it clear that even if cochlear, auditory nerve, and early brainstem processes are intact, a number of additional levels of organization are needed for optimal performance. Distortions in the frequency resolution of the representation of a talker's voice or in the timing of neural spikes coding the time of arrival at the two ears can have implications not only for instantaneous identification and segregation but also for the ability to form coherent spectrotemporal and spatial patterns. Even fairly small changes in the time it takes to form representations of sources in the environment and to track them over time can have substantial effects on the ability to switch attention rapidly among behaviorally relevant stimuli [56]. Selective attention may or may not be important for the creation of distinct auditory percepts [54], but it is clearly essential that those percepts are created before attention can be allocated to them at will. Currently, no studies have examined the effects that distorted temporal patterns of neural firing associated with blast exposure might have on auditory cognitive processes such as learning, memory, and attention. Impairments to these cognitive faculties would interfere with the ability to communicate effectively in social settings, and as listeners with hearing loss will attest, without the ability to effectively group and select sound sources in an auditory scene, such situations can quickly become intimidating and overwhelming [57]. Similar difficulties can be expected to occur after blast exposure, even in the absence of peripheral hearing loss. 


\section{Effects of Central Auditory Dysfunction on Lives of Veterans}

The media and the literature are replete with reports indicating that Operation Iraqi Freedom/Operation Enduring Freedom (OIF/OEF; wars in Iraq and Afghanistan, respectively) Veterans, especially those who have had repeated deployments, may undergo a variety of challenges while reintegrating into civilian life. This process is not expected to be any easier for Veterans of the recently christened Operation New Dawn (OND; transition from combat operations to stability operations in Iraq). One of the greatest challenges is the transition from military life back to civilian family life. This can be quite difficult, as spouses may have assumed new roles within the family, children may have been born, younger children may have become teenagers, and financial concerns may have developed. Recent reports suggest that this reintegration is not always successful: the divorce rate among Veterans has been found to increase after time spent in the combat zone. ${ }^{*}$ Consequently, it is clear that communication within the family is of critical importance and an auditory processing problem may limit its effectiveness.

It is also common for Veterans to seek out civilian jobs or enroll in higher education (a goal that leads many to enlist in the first place). Recent articles suggest that the jobless rate for Veterans aged 18 to 24 is greater than 21 percent. $^{\dagger}$ Whether returning to a prior position (which likely has changed since deployment), starting a new job, or enrolling in college, new skills need to be learned and information must be understood and remembered. This learning often needs to be rapid and may occur in a complex acoustical environment. For some Veterans, learning must occur while also addressing or accommodating other injuries encountered during their deployments (e.g., amputations). Beyond that, many of these returning soldiers are also experiencing posttraumatic stress disorder

\footnotetext{
*Shane L III. Researchers: alcohol misuse, divorce rates higher among returning troops [Internet]. Washington (DC): Stars and Stripes; 2005 [cited 2010 Aug 21]; Available from: http://www.stripes.com/news/ researchers-alcohol-misuse-divorce-rates-higher-among-returningtroops-1.42192.

${ }^{\dagger}$ Associated Press. Unemployment rate for young veterans hits 21.1 percent [Internet]. Washington (DC): The Washington Post Company; 2010 [cited 2010 Mar 13]; Available from: http:// www.washingtonpost.com/wp-dyn/content/article/2010/03/12/ AR2010031204123.html.
}

(PTSD), a condition acquired by exposure to a traumatic event and characterized by intrusion of distressing thoughts, avoidance of situations similar to those associated with the traumatic event, and hyperarousal in nonthreatening situations. The presence of PTSD in combination with an auditory processing disorder may only heighten the individual's awareness of environmental sounds and make it especially difficult to focus on the task at hand. Further, outlets for stress, such as music, may no longer be enjoyable. Clearly, blast-related injuries that impair the central auditory system can affect the quality of life of returning servicemembers and should be considered and addressed by clinicians to help the Veteran better assimilate into civilian life.

\section{Tests for Diagnostic Assessment of Central Auditory Function}

General considerations. As discussed in the previous sections, the central auditory system is composed of a set of complex and interconnected subsystems, each of which is essential for optimal performance in complex acoustical environments. While such environments provide the clearest demonstrations of when the system is performing abnormally, they do not provide the necessary diagnostic information to determine which aspect(s) of the system are dysfunctional. A solution to this problem involves the use of a battery of diagnostic tests, which range in complexity and involve as many of the underlying subsystems as possible. The 2010 American Academy of Audiology Clinical practice guidelines diagnosis, treatment and management of children and adults with central auditory processing disorder [58] and the 2005 American Speech-Language-Hearing Association's (Central) auditory processing disorders: Working group on auditory processing disorders [59] both recommended that a central auditory test battery should include tests involving both speech and nonspeech stimuli focusing on (but not limited to): binaural hearing, dichotic stimuli, auditory discrimination, competing and degraded acoustic signals, and the processing of auditory patterns and temporal stimuli. Electrophysiological testing can also be an important component of constructing a comprehensive central auditory processing test battery, as it provides a fundamentally different type of evidence about the functioning of the auditory system [58].

When selecting tests for clinical use, it is important to maximize the sensitivity and specificity of the battery by limiting the measures used to those that are most likely to 
be related to the symptoms presented by the patient [58], since the specificity decreases as more tests are added. On the other hand, an important aspect of diagnosing dysfunction in such a complex system involves the use of crossvalidation, in which two different tests can be used to corroborate an unusual result or to focus more precisely on an area in which other evidence suggests that the patient may be having particular difficulty.

\section{Behavioral central auditory test results for patients} with blast exposure. A study conducted at the Department of Veterans Affairs (VA) Rehabilitation Research and Development (RR\&D) National Center for Rehabilitative Auditory Research and the (former) Walter Reed Army Medical Center provides an example of how a battery of tests can be used to examine central auditory system dysfunction [60]. Participants who had been exposed to blasts were compared with age- and hearing-loss matched control participants who had not been blast exposed. Roughly half of the patients with blast exposure had been diagnosed with mild TBI, while half of those exposed to blasts did not have a TBI diagnosis. No participant had more than a mild peripheral hearing loss, and most had normal hearing. Five behavioral tests were administered to the participants: the Dichotic Digits test [61], the Staggered Spondaic Words test [62], the Gapsin-Noise test [63], the Masking Level Difference test [64], and the Frequency Patterns test [39]. Each test has been used in the general population in the diagnosis of central auditory dysfunction and has been shown to discriminate between participants with brain injuries and control participants of similar age and peripheral hearing status without brain injury. Analyses by Gallun et al. suggest that participants exposed to blasts were statistically more likely than were controls to perform abnormally on the Staggered Spondaic Words test, the Gaps-in-Noise test, and the Masking Level Difference test [60]. The groups did not differ reliably on the proportion of participants performing abnormally on the other two tests, suggesting that these results were not due to generalized difficulties with the attention or memory demands of psychoacoustical testing. The relatively minor peripheral hearing loss that was present for some participants could not explain the differences between groups. In addition, the results indicated that those participants with a negative TBI diagnosis were equally at risk for abnormal central auditory performance as were those diagnosed with TBI. These patterns of abnormal performance provided strong indication of the potential for a blast exposure to result in differences in central auditory function as compared with non-blast-exposed controls. To date, few studies have examined this issue in sufficient detail or with a large enough sample to draw firm conclusions on the rates of dysfunction or the most effective methods of evaluating central auditory processing abilities for a blast-exposed or TBI Veteran population.

Proposed treatment options for central auditory dysfunction. Currently, there are no clear guidelines for the management of central auditory dysfunction in a population with blast exposure. The guidelines that do exist emphasize the individualized nature of the treatment plan and the importance of working with a team of specialists [58-59], which is especially important for Veterans with multiple war-related injuries. A recent survey described by Saunders and Echt found that, although nearly all of the VA audiologists who responded had experiences in which OIF/OEF Veterans with normal audiograms complained of difficulties hearing, there was no clear consensus as to what treatment to offer [65]. Treatment approaches described included hearing aids, remotemicrophone technology, and auditory training. It is our opinion that more work is needed to address the management of central auditory manifestations of TBI and/or blast exposure in this population. In addition, as Cherney et al. have described, it is important for clinicians involved in treating patients with blast-related head injuries to remember that communication deficits can be related to nonauditory difficulties as well, including memory, attention, and emotional difficulties [66]. Accordingly, it is important to ensure that an interdisciplinary team is available to allow audiologists to work in partnership with speech-language pathologists, optometrists, psychologists, and neuropsychological experts to ensure that all of the potential causes of communicative dysfunction are addressed.

Hearing aids and remote microphones. The use of low-gain hearing aids (equipped with the option for directional-microphone use) and/or remote-microphonetechnology represent a "bottom-up" approach to environmental modification, focusing on enhancing the signal and/or reducing interference [58-59]. When a remote microphone is used, for example, the listener is able to place the microphone near the primary source of information (the signal) and, with a personally worn receiver in the ear, improve the signal-to-noise ratio of the primary sound over the competing sounds in the environment. This allows the primary sound to be heard and more likely to be understood at intensity levels 
lower than would be possible without the use of a remote microphone [67]. The findings of Gallun et al., that blast exposure is particularly likely to result in difficulties with competing speech (e.g., the Staggered Spondaic Words test), suggest that a remote microphone system may be particularly effective [60]. Although two recent articles exploring the use of remote-microphone technology in individuals with central auditory dysfunction suggest this may be the case, it still needs to be confirmed through clinical research [68-69]. Research regarding the benefit of low-gain hearing aids as a remediation strategy for this patient population is also needed, as recent research has only examined their efficacy in children having central auditory dysfunction and even then some variable results were noted [70]. "Top-down" approaches to environmental modification also can be employed [58-59]. These include improving the acoustics of commonly used environments to reduce reverberation, moving interfering sound sources away from communication areas, and educating the patient, the support team, family members, employers, and educators on the use of techniques to improve signal-to-noise ratios and increase multimodal and redundant transfer of information.

Auditory training. The evidence that auditory training programs can result in neurophysiological changes is substantial [58]. While the number of approaches and commercial programs is rapidly increasing, it is not yet known which can be used to mitigate auditory dysfunction for Veterans who have been exposed to high-intensity blasts. Much of the research that has been done has focused on improving the auditory abilities of schoolaged children who are having difficulties in an academic setting or demonstrating that training can change the performance of college-aged volunteers with normal hearing. The best auditory training approach for Veterans who have been exposed to blasts is likely to be unique. Additionally, the stimuli and training materials used may need to consider the needs of a young Veteran population with multiple war-related injuries. As with the use of amplification strategies with this population, however, the clinical research on such interventions is only just beginning.

\section{Prevalence of Central Auditory Dysfunction Among Veterans}

A pivotal question in considering these issues is the degree to which Veterans exposed to blasts are in fact suffering from difficulties associated with impairments in central auditory processing. It is worrisome that no population estimates are available for the prevalence of central auditory dysfunction from blast exposure and few studies exist that relate central auditory dysfunction rates to TBI in the general population. There is evidence, however, that sports-related concussion (mild TBI) can be associated with abnormal scores on auditory processing tests [71], suggesting that auditory processing testing is appropriate anytime impaired brain function is suspected.

As described in the section on proposed treatment options, one indication that central auditory dysfunction may be more prevalent than is currently known comes from the survey reported by Saunders and Echt [65]. In the spring of 2009, 220 VA audiologists who subscribe to the VA audiology email list were asked "How often do you encounter OIF/OEF Veterans complaining of hearing difficulties who have normal or almost normal thresholds?” In less than a week, 89 audiologists responded, representing an estimated 82 different sites. Ninety-two percent of respondents reported encountering one or more OIF/OEF Veteran fitting this profile every month. Thirty-nine percent reported 4 or more per month. Only 2 of the 89 respondents had never encountered an OIF/OEF Veteran with normal or near-normal hearing thresholds complaining of hearing difficulties. While this was an informal survey, and the issue of Veterans attempting to obtain compensation cannot be ignored, this report provides an indication that the prevalence of central auditory dysfunction in the OIF/OEF/OND Veteran population may be substantial. Similar evidence comes from Cherney et al., who noted the prevalence of difficulties with conversing in noise or in groups among those with mild TBI [66]. There is also a strong relationship between TBI due to blast exposure and the peripheral hearing loss that can also result from blast exposure [11,72]. Lew et al. found that among those Veterans receiving treatment because of blast-related TBI after the start of OIF/OEF/OND, 62 percent complained of hearing loss compared with only 28 percent of those receiving treatment because of non-blast-related TBI prior to the start of OIF/OEF/OND [11]. Additionally, those servicemembers with non-blast-related TBI who received treatment during the wars were more likely to report hearing loss (44\%) than those with non-blast-related TBI who received treatment before the start of OIF/OEF/ OND. Similar results were obtained by Sayer et al., who found that blast-related injury was significantly more likely to result in auditory dysfunction than were other mechanisms of injury [72]. To date, there have been no reports of the relative likelihoods of peripheral and central auditory dysfunction following blast exposure. 
Given the potential for high rates of CAPD in those exposed to blasts, it is important to ask how many Veterans have been exposed to blasts and are thus at risk for CAPD. According to Hoge et al., exposure on two or more occasions to nearby detonations of improvised explosive devices was reported by 62.1 percent $(1,556$ / $2,504)$ of the U.S. Army infantry soldiers surveyed in 2006, 3 to 4 months after their return from a 1-year tour of duty in Iraq [73]. Consistent with this high rate of blast exposure, Lew et al. reported that 20 percent of OIF/OEF Veterans screened positive for TBI between April 2007 and the end of 2009 [7], indicating that they were exposed to an event likely to cause TBI. In a population of 36,919 Veterans who screened positive and then received a structured comprehensive evaluation to determine the presence of mild TBI, 34 percent were judged to have deployment-related TBI. Based on blast exposure and TBI status, rates of auditory impairment in this sample ranged from 21 to 33 percent [7].

Estimates of the prevalence of TBI and auditory impairment in the OIF/OEF/OND Veteran population can be calculated from these data. With the rate of positive screenings at 20 percent and assuming that the data in Lew et al. [7] constitute a representative sample, the rate of deployment-related TBI is calculated to be approximately 7 percent, and the rate of auditory impairment between 4 and 7 percent. An additional 12 percent of the population (4,531 cases) studied by Lew et al. had both deployment- and non-deployment-related TBI [7]; a third group (2,309 cases) had non-deployment-related TBI alone, and 20 percent (7,747 cases) were missing data and so could not be evaluated. Consequently, of those who screened positive for TBI, only 25 percent $(9,106$ cases) could be definitively excluded from a TBI diagnosis. This leads to an estimate of potential TBI (from deployment and non-deployment causes) in the OIF/ OEF/OND population that falls between 7 and 15 percent. This is consistent with the VA 2011 TBI Comprehensive Evaluation Summary [74], in which it was reported that 41,581 of the 535,582 Veterans screened prior to May, 2011, were confirmed to have a diagnosis of TBI, leading to an estimated prevalence of TBI in the OIF/OEF/OND Veteran population of 7.8 percent. To date, very few data sets exist that can be used to estimate the prevalence of CAPD in the OIF/OEF/OND Veteran population. The rate may be quite high, however, given the combination of high rates of blast exposure [73] and TBI [74] and the data of Gallun et al. [60] and Turgeon et al. [71], which suggest that abnormal central auditory processing abilities are potentially associated with even mild brain injury.

\section{DISCUSSION}

Most of the Veterans exposed to blasts during the current wars are younger than 60 and have spent fewer than 10 years living with their acquired injuries from deployment. For this reason, it is impossible to know for sure what trajectory their auditory abilities may take over the coming years. The natural plasticity of the brain may be of benefit in improving the auditory abilities of some Veterans as time passes following blast exposure. However, aging effects, other possible brain insults (e.g., stroke), and continuing noise exposure all may confound the natural recovery process and/or exacerbate the sustained effects of blast exposure and TBI. It is possible that those who have been exposed to high-intensity blasts will present unique patterns of dysfunction for which the current diagnostic and treatment tools are inadequate. In order to provide appropriate and innovative care for these Veterans, it is essential that as time passes the needs of these individuals with blast exposure are periodically assessed with a view to new developments.

There are several areas in which research is needed to improve the ability of clinicians to diagnose and rehabilitate CAPDs. The most pressing need is for corroboration and extension of the results of Gallun et al. [60], in which the overall rate of abnormal performance for those subjects exposed to blasts was more than four times that of the controls without blast exposure. It is essential to determine the degree to which abnormal performance on central auditory tests in the laboratory and the clinic correlates with patient complaints and with difficulties in more naturalistic environments. To achieve this goal, research needs to be conducted in which a wider range of blast-exposed Veterans are tested on a variety of measures with greater ecological validity.

In addition to the need for basic confirmatory research, it is important to develop clinical measures that can be used to determine whether a patient complaining of communication difficulties is suffering from a (primarily) auditory disorder or deficits in other domains such as attention and memory. One area of diagnostic testing that could be explored is auditory and visual electrophysiological responses. Lew et al. reported that, in a group of 
TBI patients with favorable recovery, auditory and visual stimuli evoked late responses that were both lower in amplitude and longer in latency compared with a matched group of control subjects [75]. Gallun et al. also observed that blast-exposed participants had long latency responses that were reduced in amplitude and increased in latency relative to controls [60]. Auditory brainstem responses were not different between the two groups [60], suggesting that the differences were specifically related to central rather than peripheral effects of the blast. Electrophysiological measures in a range of sensory modalities have been shown to relate to outcomes after TBI (reviewed by Folmer et al. [76]), but more research is needed before clear clinical guidelines for blast-exposed individuals can be developed.

Finally, it would be beneficial to make use of the powerful new imaging technologies such as functional magnetic resonance imaging (fMRI) and diffusion tensor imaging (DTI) in order to better understand the neural underpinnings of those rehabilitative techniques that produce beneficial functional outcomes. One issue that has reduced their use clinically is that fMRI and DTI are difficult to use to diagnose injuries, especially in cases of diffuse brain injury in which no obvious damage is observed on a radiological image. Currently, these types of functional studies can be used for monitoring purposes to determine possible changes due to intervention/therapy. Additionally, the functional electrophysiological measures could be used to obtain baseline information on servicemembers prior to deployment, which would allow for comparison studies if injuries are sustained.

\section{CONCLUSIONS}

Presently, there is very little evidence indicating which tests and therapies should be used to provide a comprehensive clinical diagnosis and rehabilitation of the central auditory dysfunction potentially afflicting those Veterans exposed to high-intensity blasts. Were the currently available tests and techniques experimentally validated and, where necessary, new approaches developed, the advances made would surely benefit other populations suffering from central auditory impairments. Defining the relationships between performance on clinical central auditory processing tests and functional disabilities associated with listening in complex environments is imperative. Additionally, it is necessary to improve the theoretical and functional models of the sites and mechanisms of impairment in order to deliver targeted rehabilitation specific to the dysfunction observed. The identification and validation of accurate diagnostic tools and appropriately targeted rehabilitation therapies and technological devices will likely improve overall communication ability for the Veteran and help heighten awareness of the auditory environment. Treatments should take advantage of the plasticity of the brain and include retraining and/or technological strategies to offset any central auditory disorders that are present. Accurate diagnostics are necessary for development of effective treatments that address the sorts of dysfunction that are actually present-rather than those that are simply hypothesized to occur.

\section{ACKNOWLEDGMENTS}

\section{Author Contributions:}

Study concept and design: F. J. Gallun, T. C. Walden, S. A. Fausti, M. R. Leek.

Acquisition of data: F. J. Gallun, M. S. Lewis, A. C. Diedesch, L. R. Kubli, D. J. McDermott, T. C. Walden, M. R. Leek. Analysis and interpretation of data: F. J. Gallun, M. S. Lewis, R. L. Folmer, A. C. Diedesch, L. R. Kubli, D. J. McDermott, T. C. Walden, M. R. Leek.

Drafting of manuscript: F. J. Gallun, M. S. Lewis, A. C. Diedesch, L. R. Kubli, D. J. McDermott, T. C. Walden, H. L. Lew, M. R. Leek. Critical revision of manuscript for important intellectual content: R. L. Folmer, T. C. Walden, S. A. Fausti, H. L. Lew, M. R. Leek. Obtained funding: T. C. Walden, S. A. Fausti, M. R. Leek.

Financial Disclosures: The authors have declared that no competing interests exist.

Funding/Support: This material was based on work supported by VA RR\&D Merit Review Award (grant 01807: PIs Leek, Fausti), VA RR\&D Career Development II Awards (grant C4963-W: PI Gallun; and grant C7067-W: PI Lewis), VA RR\&D Senior Research Career Scientist Award (grant C4042-L: PI Leek), and the VA RR\&D National Center for Rehabilitative Auditory Research.

Additional Contributions: The authors are grateful to Lynn Kitagawa for creating the drawing that appears in the Figure. Disclaimer: The opinions and assertions presented are private views of the authors and are not to be construed as official or as necessarily reflecting the views of the VA, the Department of the Army, or the Department of Defense.

\section{REFERENCES}

1. DePalma RG, Burris DG, Champion HR, Hodgson MJ. Blast injuries. N Engl J Med. 2005;352(13):1335-42.

[PMID:15800229] http://dx.doi.org/10.1056/NEJMra042083 
2. Cohen JT, Ziv G, Bloom J, Zikk D, Rapoport Y, Himmelfarb MZ. Blast injury of the ear in a confined space explosion: auditory and vestibular evaluation. Isr Med Assoc J. 2002;4(7):559-62. [PMID:12120473]

3. Chandler DW, Edmond CV. Effects of blast overpressure on the ear: case reports. J Am Acad Audiol. 1997;8(2):81-88. [PMID:9101454]

4. Chandler D. Blast-related ear injury in current U.S. military operations: Role of audiology on the interdisciplinary team. ASHA Leader. 2006 Jul 11:8-9.

5. Cave KM, Cornish EM, Chandler DW. Blast injury of the ear: clinical update from the global war on terror. Mil Med. 2007;172(7):726-30. [PMID:17691685]

6. Lew HL, Weihing J, Myers PJ, Pogoda TK, Goodrich GL. Dual sensory impairment (DSI) in traumatic brain injury (TBI)-An emerging interdisciplinary challenge. NeuroRehabilitation. 2010;26(3):213-22. [PMID:20448311]

7. Lew HL, Pogoda TK, Baker E, Stolzmann KL, Meterko M, Cifu DX, Amara JH, Hendricks AM. Prevalence of dual sensory impairment and its association with traumatic brain injury and blast exposure in OEF/OIF veterans. J Head Trauma Rehabil. 2011;26(6):489-96. [PMID:21386715] http://dx.doi.org/10.1097/HTR.0b013e318204e54b

8. Pogoda TK, Hendricks AM, Iverson KM, Stolzmann KL, Krengel MH, Baker E, Meterko M, Lew HL. Multisensory impairment reported by veterans with and without mild traumatic brain injury history. J Rehabil Res Dev. 2012; 49(7):971-84.

http://dx.doi.org/10.1682/JRRD.2011.06.0099

9. Lew HL. Rehabilitation needs of an increasing population of patients: Traumatic brain injury, polytrauma, and blastrelated injuries. J Rehabil Res Dev. 2005;42(4):xiii-xvi. [PMID:16320135] http://dx.doi.org/10.1682/JRRD.2005.01.0124

10. Fausti SA, Wilmington DJ, Gallun FJ, Myers PJ, Henry JA. Auditory and vestibular dysfunction associated with blastrelated traumatic brain injury. J Rehabil Res Dev. 2009; 46(6):797-810. [PMID:20104403] http://dx.doi.org/10.1682/JRRD.2008.09.0118

11. Lew HL, Jerger JF, Guillory SB, Henry JA. Auditory dysfunction in traumatic brain injury. J Rehabil Res Dev. 2007; 44(7):921-28. [PMID:18075949]

http://dx.doi.org/10.1682/JRRD.2007.09.0140

12. Chafi MS, Karami G, Ziejewski M. Biomechanical assessment of brain dynamic responses due to blast pressure waves. Ann Biomed Eng. 2010;38(2):490-504. [PMID:19806456] http://dx.doi.org/10.1007/s10439-009-9813-z

13. Povlishock JT, Katz DI. Update of neuropathology and neurological recovery after traumatic brain injury. J Head Trauma Rehabil. 2005;20(1):76-94. [PMID:15668572] http://dx.doi.org/10.1097/00001199-200501000-00008
14. Taber KH, Warden DL, Hurley RA. Blast-related traumatic brain injury: what is known? J Neuropsychiatry Clin Neurosci. 2006;18(2):141-45. [PMID:16720789] http://dx.doi.org/10.1176/appi.neuropsych.18.2.141

15. Winer JA, Lee CC. The distributed auditory cortex. Hear Res. 2007;229(1-2):3-13. [PMID:17329049] http://dx.doi.org/10.1016/j.heares.2007.01.017

16. Elhilali M, Fritz JB, Chi TS, Shamma SA. Auditory cortical receptive fields: stable entities with plastic abilities. J Neurosci. 2007;27(39):10372-82. [PMID:17898209] http://dx.doi.org/10.1523/JNEUROSCI.1462-07.2007

17. Fitzgerald DC. Head trauma: hearing loss and dizziness. J Trauma. 1996;40(3):488-96. [PMID:8601878] http://dx.doi.org/10.1097/00005373-199603000-00034

18. Rodriguez-Paez AC, Brunschwig JP, Bramlett HM. Light and electron microscopic assessment of progressive atrophy following moderate traumatic brain injury in the rat. Acta Neuropathol. 2005;109(6):603-16. [PMID:15877231] http://dx.doi.org/10.1007/s00401-005-1010-z

19. Okie S. Traumatic brain injury in the war zone. N Engl J Med. 2005;352(20):2043-47. [PMID:15901856] http://dx.doi.org/10.1056/NEJMp058102

20. Peru A, Beltramello A, Moro V, Sattibaldi L, Berlucchi G. Temporary and permanent signs of interhemispheric disconnection after traumatic brain injury. Neuropsychologia. 2003;41(5):634-43. [PMID:12559156] http://dx.doi.org/10.1016/S0028-3932(02)00203-8

21. Kandel E, Schwartz J, Jessell T, Mack S, Dodd J. Principles of neural science. New York (NY): Elsevier; 1991.

22. Petkov CI, Kayser C, Augath M, Logothetis NK. Functional imaging reveals numerous fields in the monkey auditory cortex. PLoS Biol. 2006;4(7):e215. [PMID:16774452] http://dx.doi.org/10.1371/journal.pbio.0040215

23. Petkov CI, Kayser C, Steudel T, Whittingstall K, Augath M, Logothetis NK. A voice region in the monkey brain. Nat Neurosci. 2008;11(3):367-74. [PMID:18264095] http://dx.doi.org/10.1038/nn2043

24. Leaver AM, Rauschecker JP. Cortical representation of natural complex sounds: effects of acoustic features and auditory object category. J Neurosci. 2010;30(22):7604-12. [PMID:20519535] http://dx.doi.org/10.1523/JNEUROSCI.0296-10.2010

25. Nelken I, Fishbach A, Las L, Ulanovsky N, Farkas D. Primary auditory cortex of cats: feature detection or something else? Biol Cybern. 2003;89(5):397-406. [PMID:14669020] http://dx.doi.org/10.1007/s00422-003-0445-3

26. Scott SK, Johnsrude IS. The neuroanatomical and functional organization of speech perception. Trends Neurosci. 2003;26(2):100-107. [PMID:12536133] http://dx.doi.org/10.1016/S0166-2236(02)00037-1 
27. Elhilali M, Shamma SA. A cocktail party with a cortical twist: how cortical mechanisms contribute to sound segregation. J Acoust Soc Am. 2008;124(6):3751-71. [PMID:19206802] http://dx.doi.org/10.1121/1.3001672

28. Fritz J, Shamma S, Elhilali M, Klein D. Rapid task-related plasticity of spectrotemporal receptive fields in primary auditory cortex. Nat Neurosci. 2003;6(11):1216-23. [PMID:14583754] http://dx.doi.org/10.1038/nn1141

29. Zatorre RJ. There's more to auditory cortex than meets the ear. Hear Res. 2007;229(1-2):24-30. [PMID:17341441] http://dx.doi.org/10.1016/j.heares.2007.01.018

30. Kidd G Jr, Mason CR, Richards VM, Gallun FJ, Durlach NI. Informational masking. In: Yost W, Popper A, Fay R, editors. Auditory perception of sound Sources. New York (NY): Springer Verlag; 2008. p. 143-90.

31. Demany L, Semal C. The role of memory in auditory perception. In: Yost W, Popper A, Fay R, editors. Auditory perception of sound sources. New York (NY): Springer Verlag; 2008. p. 115-42.

32. Griffiths TD, Warren JD. What is an auditory object? Nat Rev Neurosci. 2004;5(11):887-92. [PMID:15496866] http://dx.doi.org/10.1038/nrn1538

33. Oxenham AJ, Micheyl C, Keebler MV. Can temporal fine structure represent the fundamental frequency of unresolved harmonics? J Acoust Soc Am. 2009;125(4):2189-99. [PMID:19354395] http://dx.doi.org/10.1121/1.3089220

34. Yost WA. Pitch perception. Atten Percept Psychophys. 2009;71(8):1701-15. [PMID:19933556] http://dx.doi.org/10.3758/APP.71.8.1701

35. Joris PX, Schreiner CE, Rees A. Neural processing of amplitude-modulated sounds. Physiol Rev. 2004;84(2): 541-77. [PMID:15044682] http://dx.doi.org/10.1152/physrev.00029.2003

36. Moore BC, Peters RW. Pitch discrimination and phase sensitivity in young and elderly subjects and its relationship to frequency selectivity. J Acoust Soc Am. 1992;91(5):2881-93. [PMID:1629481] http://dx.doi.org/10.1121/1.402925

37. Leek MR, Summers V. Pitch strength and pitch dominance of iterated rippled noises in hearing-impaired listeners. J Acoust Soc Am. 2001;109(6):2944-54. [PMID:11425136] http://dx.doi.org/10.1121/1.1371761

38. Moore B. Cochlear hearing loss: physiological, psychological and technical issues. West Sussex (UK): Wiley-Interscience; 2007.

39. Musiek FE, Pinheiro ML. Frequency patterns in cochlear, brainstem, and cerebral lesions. Audiology. 1987;26(2):79-88.
[PMID:3606474]

http://dx.doi.org/10.3109/00206098709078409

40. Bamiou DE, Musiek FE, Stow I, Stevens J, Cipolotti L, Brown MM, Luxon LM. Auditory temporal processing deficits in patients with insular stroke. Neurology. 2006; 67(4):614-19. [PMID:16924014] http://dx.doi.org/10.1212/01.wnl.0000230197.40410.db

41. Tervaniemi M, Hugdahl K. Lateralization of auditory-cortex functions. Brain Res Brain Res Rev. 2003;43(3):23146. [PMID:14629926]

http://dx.doi.org/10.1016/j.brainresrev.2003.08.004

42. Loui P, Guenther FH, Mathys C, Schlaug G. Action-perception mismatch in tone-deafness. Curr Biol. 2008;18(8): R331-32. [PMID:18430629]

http://dx.doi.org/10.1016/j.cub.2008.02.045

43. Loui P, Hohmann A, Schlaug G. Inducing disorders in pitch perception and production: a reverse-engineering Approach. Proceedings of 159th Meeting of Acoustical Society of America/Noise-CON 2010; 2010 Apr 19-23; Baltimore, MD. Melville (NY): Acoustical Society of America; 2010. 9(1):050002-8. http://dx.doi.org/10.1121/1.3431713

44. Colburn H, Durlach N. Binaural phenomena. In: Carterette EC, Friedman MP, editors. Handbook of perception: hearing. New York (NY): Academic Press, Inc; 1978. p. 467-515.

45. Stecker C, Gallun FJ. Binaural hearing, sound localization, and spatial hearing. In: Tremblay, K, Burkhardt, R, editors. Translational perspectives in auditory neuroscience: normal aspects of hearing. San Diego (CA): Plural Publishing, Inc; 2012.

46. Darwin CJ. Spatial hearing and perceiving sources. In: Yost W, Popper A, Fay R, editors. Auditory perception of sound sources. New York (NY): Springer Verlag; 2008. p. 215-32.

47. Kidd G Jr, Arbogast TL, Mason CR, Gallun FJ. The advantage of knowing where to listen. J Acoust Soc Am. 2005; 118(6):3804-15. [PMID:16419825] http://dx.doi.org/10.1121/1.2109187

48. Marrone N, Mason CR, Kidd G. Tuning in the spatial dimension: evidence from a masked speech identification task. J Acoust Soc Am. 2008;124(2):1146-58.

[PMID:18681603]

http://dx.doi.org/10.1121/1.2945710

49. Kidd G, Mason CR, Brughera A, Hartmann WM. The role of reverberation in release from masking due to spatial separation of sources for speech identification. Acta Acustica United with Acustica. 2005;91(3):526-36.

50. Marrone N, Mason CR, Kidd G Jr. The effects of hearing loss and age on the benefit of spatial separation between multiple talkers in reverberant rooms. J Acoust Soc Am. 2008;124(5):3064-75. [PMID:19045792] http://dx.doi.org/10.1121/1.2980441 
51. Köhler W. Gestalt psychology. New York (NY): Liveright Publishing Corporation; 1947.

52. Dowling W, Harwood D. Music cognition. New York (NY): Academic Press; 1986.

53. Bregman A. Auditory scene analysis: the perceptual organization of sound. In: Yost W, Popper A, Fay R, editors. Cambridge (MA): MIT Press; 1990.

54. Cusack R, Carlyon RP. Auditory perceptual organization inside and outside the labratory. In: Neuhoff JG, editor. Ecological psychoacoustics. San Diego (CA): Elsevier Academic Press; 2004. p. 16-48.

55. Wang D, Brown GJ. Computational auditory scene analysis: principles, algorithms, and applications. Wang D, Brown GJ, editors. Piscataway (NJ): John Wiley \& Sons, Inc; 2006.

56. Shinn-Cunningham BG, Best V. Selective attention in normal and impaired hearing. Trends Amplif. 2008;12(4):283-99. [PMID:18974202] http://dx.doi.org/10.1177/1084713808325306

57. Noble W, Gatehouse S. Effects of bilateral versus unilateral hearing aid fitting on abilities measured by the Speech, Spatial, and Qualities of Hearing Scale (SSQ). Int J Audiol. 2006;45(3):172-81. [PMID:16579492]

http://dx.doi.org/10.1080/14992020500376933

58. American Academy of Audiology (AAA). American Academy of Audiology Clinical practice guidelines diagnosis, treatment and management of children and adults with central auditory processing disorder [Internet]. Reston (VA): AAA; 2010 [cited 2010 Aug]; Available from: http:// www.audiology.org/resources/documentlibrary/Pages/CentralAuditoryProcessingDisorder.aspx.

59. American Speech-Language-Hearing Association (ASHA). (Central) auditory processing disorders: Working group on auditory processing disorders [Internet]. Rockville (MD): ASHA; 2005 [cited 2010 Aug]; Available from: http:// www.asha.org/docs/html/TR2005-00043.html.

60. Gallun FJ, Diedesch AC, Kubli L, Walden T, Folmer RL, Lewis MS, McDermott DJ, Fausti SA, Leek MR. Performance on tests of central auditory processing by individuals exposed to high-intensity blasts. J Rehabil Res Dev. 2012;49(7):1005-24.

http://dx.doi.org/10.1682/JRRD.2012.03.0038

61. Musiek FE. Assessment of central auditory dysfunction: the dichotic digit test revisited. Ear Hear. 1983;4(2):79-83. [PMID:6840415] http://dx.doi.org/10.1097/00003446-198303000-00002

62. Katz J. The SSW test manual. 5th ed. Vancouver (Canada): Precision Acoustics; 1998.

63. Musiek FE, Shinn JB, Jirsa R, Bamiou DE, Baran JA, Zaida E. GIN (Gaps-In-Noise) test performance in subjects with confirmed central auditory nervous system involve- ment. Ear Hear. 2005;26(6):608-18. [PMID:16377996]

http://dx.doi.org/10.1097/01.aud.0000188069.80699.41

64. Wilson RH, Weakley DG. The $500 \mathrm{~Hz}$ masking-level difference and word recognition in multitalker babble for 40to 89-year-old listeners with symmetrical sensorineural hearing loss. J Am Acad Audiol. 2005;16(6):367-82. [PMID:16178408]

http://dx.doi.org/10.3766/jaaa.16.6.5

65. Saunders GH, Echt KV. Blast exposure and dual sensory impairment: An evidence review and integrated rehabilitation approach. J Rehabil Res Dev. 2012;49(7):1043-58. http://dx.doi.org/10.1682/JRRD.2010.08.0157

66. Cherney LR, Gardner PJ, Logemann JA, Newman LA, O’Neil-Pirozzi T, Roth CR, Solomon NP; Communication Sciences and Disorders Clinical Trails Research Group. The role of speech-language pathology and audiology in the optimal management of the service member returning from Iraq or Afghanistan with a blast-related head injury: position of the Communication Sciences and Disorders Clinical Trials Research Group. J Head Trauma Rehabil. 2010;25(3):219-24. [PMID:20473095] http://dx.doi.org/10.1097/HTR.0b013e3181dc82c1

67. Lewis MS, Gallun FJ, Lilly DJ, Crandell C. A pilot investigation regarding speech-recognition performance in noise for adults with hearing loss in the FM+HA listening condition. Volta Review. 2010;110(1):31-54.

68. Johnston KN, John AB, Kreisman NV, Hall JW 3rd, Crandell CC. Multiple benefits of personal FM system use by children with auditory processing disorder (APD). Int J Audiol. 2009;48(6):371-83. [PMID:19925345] http://dx.doi.org/10.1080/14992020802687516

69. Smart JL, Kelly AS, Searchfield GD, Lyons AM, Houghton JM. Rehabilitation of adults with auditory processing disorder and normal peripheral hearing: Two case studies. Aust N Z J Audiol. 2007;29(1):53-59. http://dx.doi.org/10.1375/audi.29.1.53

70. Kuk F, Jackson A, Keenan D, Lau CC. Personal amplification for school-age children with auditory processing disorders. J Am Acad Audiol. 2008;19(6):465-80.

[PMID:19253780] http://dx.doi.org/10.3766/jaaa.19.6.3

71. Turgeon C, Champoux F, Lepore F, Leclerc S, Ellemberg D. Auditory processing after sport-related concussions. Ear Hear. 2011;32(5):667-70. [PMID:21399499] http://dx.doi.org/10.1097/AUD.0b013e31821209d6

72. Sayer NA, Chiros CE, Sigford B, Scott S, Clothier B, Pickett T, Lew HL. Characteristics and rehabilitation outcomes among patients with blast and other injuries sustained during the Global War on Terror. Arch Phys Med Rehabil. 2008;89(1):163-70. [PMID:18164349] http://dx.doi.org/10.1016/j.apmr.2007.05.025 
73. Hoge CW, McGurk D, Thomas JL, Cox AL, Engel CC, Castro CA. Mild traumatic brain injury in U.S. soldiers returning from Iraq. N Engl J Med. 2008;358(5):453-63. [PMID:18234750] http://dx.doi.org/10.1056/NEJMoa072972

74. Department of Veterans Affairs, Office of Patient Care Services, Office of Rehabilitation Services. TBI comprehensive evaluation summary. Washington (DC): Department of Veterans Affairs; July 2011.

75. Lew HL, Lee EH, Pan SS, Date ES. Electrophysiologic abnormalities of auditory and visual information processing in patients with traumatic brain injury. Am J Phys Med Rehabil. 2004;83(6):428-33. [PMID:15166686] http://dx.doi.org/10.1097/00002060-200406000-00004

76. Folmer RL, Billings CJ, Diedesch-Rouse AC, Gallun FJ, Lew HL. Electrophysiological assessments of cognition and sensory processing in TBI: applications for diagnosis, prognosis and rehabilitation. Int J Psychophysiol. 2011; 82(1):4-15. [PMID:21419179]

http://dx.doi.org/10.1016/j.ijpsycho.2011.03.005
Submitted for publication September 1, 2010. Accepted in revised form February 6, 2012.

This article and any supplemental material should be cited as follows:

Gallun FJ, Lewis MS, Folmer RL, Diedesch AC, Kubli LR, McDermott DJ, Walden TC, Fausti SA, Lew HL, Leek MR. Implications of blast exposure for central auditory function: A review. J Rehabil Res Dev. 2012;49(7): 1059-74.

http://dx.doi.org/10.1682/JRRD.2010.09.0166

ResearcherID: Frederick J. Gallun, PhD: G-3792-2012

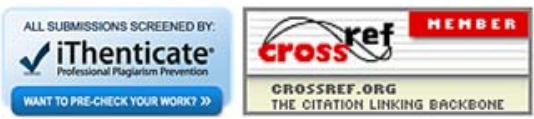

